\title{
Beyond 2020: converging crises demand integrated responses
}

\section{Statement by the RACC International Advisory Committee following the RACC-12 International Forum}

\author{
Jim Falk ${ }^{1,13} \cdot$ Rita Colwell $^{2,14} \cdot$ Adel El-Beltagy $^{3} \cdot$ Peter Gleick $^{4} \cdot$ Charles Kennel $^{5} \cdot$ Yuan T. Lee $^{6} \cdot$ Amy Luers $^{7}$. \\ Cherry Murray $^{8,15} \cdot$ Ismail Serageldin $^{9} \cdot$ Kazuhiko Takeuchi $^{10} \cdot$ Chiho Watanabe $^{11} \cdot$ Tetsuzo Yasunari $^{12}$
}

Received: 9 October 2020 / Accepted: 14 October 2020 / Published online: 29 October 2020

(c) Springer Japan KK, part of Springer Nature 2020

\begin{abstract}
The COVID-19 pandemic illustrates how the impacts of climate change are beginning to converge with other developing challenges with a likely peak with global population, requiring more integrated responses locally, regionally and globally.
\end{abstract}

Keywords Sustainability challenges $\cdot$ Climate change $\cdot$ COVID-19 Convergence $\cdot$ Integrated responses

\section{Introduction}

RACC (Regional Action for Climate Change) has been a program of activity which has focussed on the reality that many of the actions to be taken in adapting to and mitigating climate change must be implemented by local communities. RACC has worked to support getting expert scientific advice to those communities to assist them in formulating responses, and for the last 12 years has reported and further

Handled by Osamu Saito, Institute for Global Environmental Strategies, Japan.

Jim Falk

jfalk@unimelb.edu.au

1 Melbourne Sustainable Society Institute, University of Melbourne, Melbourne, Australia

2 Center for Bioinformatics and Computational Biology, University of Maryland, College Park, USA

3 International Drylands Development Commission, and Arid Land Agricultural Graduate Studies and Research Institute, Ain Shams University, Cairo, Egypt

4 Pacific Institute for Studies in Development, Environment and Security, Oakland, USA

5 Scripps Institution of Oceanography, University of California, Santa Cruz, USA, and Centre for Science and Policy, University of Cambridge, Cambridge, UK

6 Academia Sinica, [Nobel Laureate in Chemistry 1986], Taipei, Taiwan developed its insights at a forum held in conjunction with the Science, Technology and Society (STS) Forum in Kyoto. In October this year, RACC focussed on the implications for responses to climate change of the COVID-19 pandemic. The pandemic can be seen as an early illustration of the way that a range of critical risk dynamics are beginning to converge with that of climate change. As these develop and interact they will have an increasing impact on human insecurity. The comment by the RACC International Advisory Committee below briefly expands on this and its implications for research and policy implementation. More on the RACC can be found at www.stsforum.org/racc/.

7 Center for Sustainability in the Digital Age, and Future Earth, Montreal, Canada

8 Harvard University, Cambridge, USA

9 The Library of Alexandria, Alexandria, Egypt

10 Institute for Global Environmental Strategies and Institute for Future Initiatives, The University of Tokyo, Tokyo, Japan

11 National Institute for Environmental Studies, Tsukuba, Japan

12 Research Institute for Humanity and Nature, Kyoto, Japan

13 University of Wollongong, Wollongong, Australia

14 Johns Hopkins Bloomberg School of Public Health, Baltimore, USA

15 University of Arizona, Tucson, USA 


\section{Converging crises}

For the 12th successive year, on 2 October, the STS Forum hosted the RACC high-level meeting on Regional Action on Climate Change, on this occasion by video conference.

It is a year in which we see impacts of climate change converge with other critical challenges.

Indeed, we are at a potentially pivotal moment in human history. It is the year when humanity is experiencing global systemic crises resulting from converging impacts of climate change, biodiversity loss, pollution, inadequate global health infrastructures, and stark inequalities. Failure to respond effectively earlier and faster to these is now beginning to appear as worsening systemic challenges to global, regional, and local security.

Last year the STS Forum warned that it was only a matter of time until humanity faces an epidemic "we remain unprepared for and cannot control." This year that alarm is realised in the COVID pandemic, while simultaneously some regions are confronted by climate-related crisis from extreme fires and floods.

Human disruption of the interacting components of the planet's climatic, ecological, physical and biological processes is creating a new and rapidly changing planetary system. Emissions of greenhouse gases continue to drive global mean temperatures ever higher. Unless emissions decline rapidly in the coming decade, a rise of 4 degrees or more this century is currently projected. If adequate emission reduction does not occur, most parts of the world will see enhanced climate extremes, with consequent destruction of the biosphere, human dislocations, resource conflicts, and economic stresses.

As the interplay of critical dynamics becomes more intense, so do potential pressures from migration forced by declining capacity of heavily populated regions to support human wellbeing. Pandemics bridge geographical boundaries facilitated by the global flow of people, goods and services, and military conflict, which in turn can be powered by inequities, poverty, and increasingly scarce natural resources, increasingly intense climatic events, and changing patterns of precipitation. All combine with efforts to offset these events, which increase greenhouse gas emissions. As these undermine global security, they present a combined problem for all people. The local impacts may be very different, but the failure to address them globally will have both global and local repercussions.

\section{Towards an integrated response}

Despite important initiatives such as the Paris Agreement, the Sendai Framework for Disaster Risk Reduction, the Aichi Biodiversity Target, and efforts to achieve Sustainable Development Goals (SDGs), defined in the 2030 agenda, these have not been enough nor carried out on a schedule sufficient to shift human societies away from their current trajectory towards global insecurity. As these agendas are inter-connected, their development requires not only to be accelerated but coordinated. For that it will be necessary for the environmental, public health, and economics research and policy communities to work towards developing a unified framework for managing the risks.

Whilst the threat to human security is worldwide, many of the impacts require local attention. Each local community must optimise its resilience in the face of increasing risks. This requires interlinked mitigation and adaption strategies. It is clear that if adaptation strategies do not simultaneously support mitigation of emissions (and absorption of atmospheric carbon where practical), the adaptation challenge will simply grow larger.

Developing greater resilience requires much greater coordination of strategy and implementation across localities, regions, and globally. Capacity to build resilience varies dramatically across localities, significantly reflecting inequalities both in and between the developed and developing world. These include dramatically different access to income and capital and also education, communication, other infrastructure, and science, technology, and data. Important examples include lack of access to precision agriculture and technology enhancement for cities. Lack of access to these essential development tools requires urgent attention.

The latest most effective technical approaches should be applied to assist local communities to both reduce their emissions and more generally build their resilience. Examples include the "Circulating and Ecological Sphere (CES)" concept developed in Japan (integrating ecosystem-based solutions, decarbonisation, resource circulation and rural-urban linkage approaches), downscaled modelling of the developing local regional impacts (as provided by the Australian Geoscience Data Cube approach), multiple measures that can greatly improve agricultural yield from a cubic meter of water and soil, methods for reducing soil erosion, appropriate choices of substitute crop varieties, and much else. Accessible case studies of best practice in building resilience are vital to building local capacity. Given the serious gap in internet availability between different localities, enhanced access to the internet, and systems, databases and networks, linked to technical advice, are needed to assist one local community to identify best practice approaches in another. Making these capacities locally available requires urgent attention with generous support from the richer countries. 


\section{A critical moment}

In this year, we stand at a crossroads globally on which trajectory is to follow in the wake of the pandemic. There is a great deal that has been learned about the need to cooperate across societies to meet and defend against a global threat and how that can be assisted by digital networking in powerful ways, and that governments can exercise a social licence to invest more in community health and well-being. Governments are now planning to invest trillions of dollars to put their countries back on vigorous development paths. However, the direction of development is open to design. The opportunity is there to direct investment away from vested interest powering the current trajectory, and towards a more resilient future for the entire planet. Embarking on such a trajectory is within humanity's grasp. The task ahead for all organisations and communities, with learnings gained, is to build the new political will to achieve it.

Publisher's Note Springer Nature remains neutral with regard to jurisdictional claims in published maps and institutional affiliations. 